\title{
Congenital and perinatal cytomegalovirus infection
}

\author{
Chun Soo Kim, M.D., Ph.D.
}

Departments of Pediatrics, Keimyung University School of Medicine, Daegu, Korea

\section{$=$ Abstract $=$}

Cytomegalovirus (CMV) is currently the most common agent of congenital infection and the leading infectious cause of brain damage and hearing loss in children. Symptomatic congenital CMV infections usually result from maternal primary infection during early pregnancy. One half of symptomatic infants have cytomegalic inclusion disease (CID), which is characterized by involvement of multiple organs, in particular, the reticuloendothelial and central nervous system (CNS). Moreover, such involvement may or may not include ocular and auditory damage. Approximately $90 \%$ of infants with congenital infection are asymptomatic at birth. Preterm infants with perinatal CMV infection can have symptomatic diseases such as pneumonia, hepatitis, and thrombocytopenia. Microcephaly and abnormal neuroradiologic imaging are associated with a poor prognosis. Hearing loss may occur in both symptomatic and asymptomatic infants with congenital infection and may progress through childhood. Congenital infection is defined by the isolation of CMV from infants within the first 3 weeks of life. Ganciclovir therapy can be considered for infants with symptomatic congenital CMV infection involving the CNS. Pregnant women of seronegative state should be counseled on the importance of good hand washing and other control measures to prevent $\mathrm{CMV}$ infection. Heat treatment of infected breast milk at $72^{\circ} \mathrm{C}$ for 5 seconds can eliminate CMV completely. (Korean J Pediatr 2010;53:14-20)

Key Words: Cytomegalovirus, Congenital, Perinatal, Hearing loss

\section{Introduction}

Human cytomegalovirus (CMV) is a member of the Herpesviridae family of DNA viruses and ubiquitous in the general population. Most CMV infections are inapparent, but the virus can cause a wide range of diseases in neonates and immunocompromised patients. CMV is the most common cause of congenital infection worldwide, affecting 0.2 $\%$ to $2.4 \%$ of all live births ${ }^{1-4)}$. CMV is now the most common viral cause of mental retardation and hearing deficit of children in developed countries ${ }^{5-7}$.

CMV causes deformation of preformed tissues rather than malformation of developing organs ${ }^{8)}$, so CMV can affect fetuses beyond the first trimester, although earlier infection is usually more severe ${ }^{8-10)}$. Primary maternal infection is most likely to cause severe symptomatic congenital infection $^{11)}$, but recurrent infection may also rarely do so. Peri-

Received: 2 December 2009, Accepted: 6 December 2009 Address for correspondence: Chun Soo Kim, M.D., Ph.D.

Departments of Pediatrics, Keimyung University School of Medicine 194 Dongsan-dong, Jung-gu, Daegu, 700-712, Korea

Tel : +82.53-250-7526, Fax : +82.53-250-7783

E-mail : cskim@dsmc.or.kr natal CMV infection is usually not associated with clinical illness in term babies, but may also cause serious problems in preterm infants ${ }^{12-15)}$.

\section{Transmission}

Transmission of CMV occurs from person to person through body fluids, and requires close contact with contaminated secretions because the virus in not very contagious. CMV can be found in blood, urine, semen, cervical secretions, saliva, breast milk and transplanted organs, all these sites intermittently excrete viruses ${ }^{1,12)}$. Viral excretion is particularly prolonged after primary infection over years but also occurs with reactivation of infection ${ }^{1,5)}$.

Transmission of CMV to fetuses and newborn infants occurs in one of following modes ${ }^{12,15-18)}$ : (1) in utero by transplacental passage from hematogenous spread to the fetus during maternal viremia; (2) at birth by intrapartum passage after exposure to infected cervical and vaginal secretions; (3) postnatally by ingestion of CMV-positive breast milk or infected blood transfusion. 


\section{Epidemiology}

CMV infection is endemic and lacking in seasonal variation. Congenital CMV infection can result from maternal primary or reactivated infection during pregnancy ${ }^{1,5)}$. And also maternal reinfection of different strains of CMV can rarely lead to congenital symptomatic infection ${ }^{19,20)}$. The prevalence of congenital CMV infection varies between $0.2-2.4 \%$ in different countries ${ }^{1-4)}$. In developed countries, around $50-60 \%$ of pregnant, middle to high class women have antibodies to CMV, compared with around 70-85\% of those from lower socioeconomic groups ${ }^{3,4)}$. Overall, 1-4\% of susceptible women are affected with primary CMV infection during pregnancy, and around $30-40 \%$ of the fetus are transplacentally infected, and also about $10 \%$ infants manifest clinical signs and symptoms at birth ${ }^{1-5)}$. Approximately $1-3 \%$ of infants born of women with preexisting antibody to CMV are infected in utero, but they have rarely symptomatic illnesses at birth (less than 1\%) ${ }^{5,19)}$. It has been known that the risk of symptomatic infections at birth or the baby who will develop subsequent sequelae is higher if maternal infection occurs during the first half of pregnancy, and also most of severe congenital infection is caused by primary rather than recurrent infection of pregnant women $5,10,11)$. A suggested schema of congenital CMV infection and its outcome may be a possible scenario in the commu- nity (Fig. 1).

Perinatal CMV infection can result from exposure to infected secretions of maternal genital tract at delivery or breast milk that contains the virus. Around $2-28 \%$ of seropositive mothers shed CMV in cervical and vaginal secretions during delivery, and approximately 50\% of exposed infants are infected ${ }^{15)}$. Around $9-88 \%$ of seropositive women shed CMV into their milk, and approximately 50$60 \%$ of infants fed breast milk that contains the virus become infected ${ }^{15,21)}$.

Transfusion-acquired perinatal CMV infection occurs in infants of seronegative mothers who are exposed to blood products that contain the virus. The incidence of infection is about 10-30\% and occurs usually preterm infants with a birth weight of less than $1,500 \mathrm{~g}^{1,22)}$. The risk of infection is related the volume of transfused blood or number of donors, and the titer of CMV in donor blood ${ }^{15)}$.

\section{Clinical manifestation}

\section{Congenital infection}

Approximately $10 \%$ of infants with congenital CMV infection have signs and symptoms at birth, and only one half of these babies have the fulminant illness; cytomegalic inclusion disease (CID) ${ }^{13,15)}$. Another $5 \%$ of these infants show mild and atypical involvement, and $90 \%$ are born with

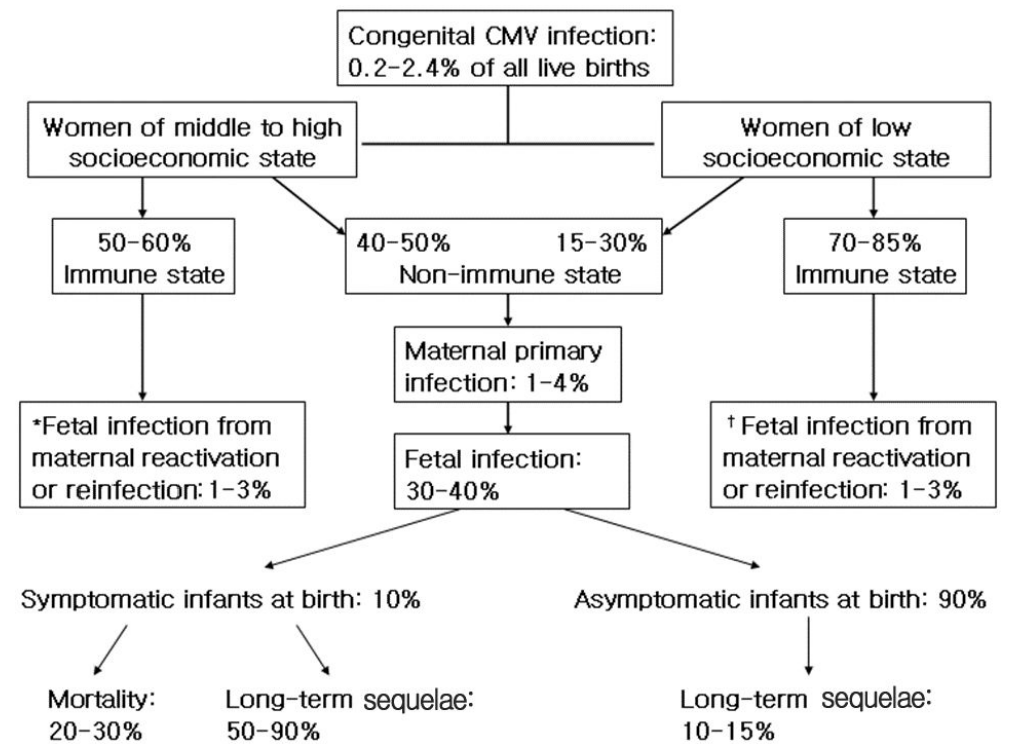

Fig. 1. A schema of congenital cytomegalovirus infection and its outcome. ${ }^{* \dagger}$ The rate of symptomatic infection at birth is less than $1 \%$. The suggested incidence rate reflects data reported in the pediatric literature ${ }^{1-6,8,9)}$. 
subclinical but chronic infection ${ }^{2,15)}$. The symptomatic infection of infants usually results from primary infection of the mother, ${ }^{5}$. And it appear that the risk is greater, the earlier in gestation the infection occurs ${ }^{5,11}$.

Infants with CID typically have a purpuric rash due to thrombocytopenia (usually with petechiae), intrauterine growth retardation (IUGR), hepatosplenomegaly, jaundice, hearing loss, microcephaly, chorioretinitis and intracerebral calcification. More commonly, infected infants may exhibit a wide spectrum of disease with only one or a few of these manifestations ${ }^{15)}$ (Table 1). Premature infants or babies who are small for gestational age with hepatosplenomegaly and abnormal liver function are most common findings of symptomatic congenital CMV infection ${ }^{4}$. Hyperbilirubinemia may be transient with a rise in the direct component. Thrombocytopenia is developed one third of infants with congenital infection, and may persist for weeks ${ }^{5)}$. There may also be a Coombs-negative hemolytic anemia, ${ }^{511}$. Pneumonia

Table 1. Clinical Manifestation of Congenital Cytomegalovirus Infection

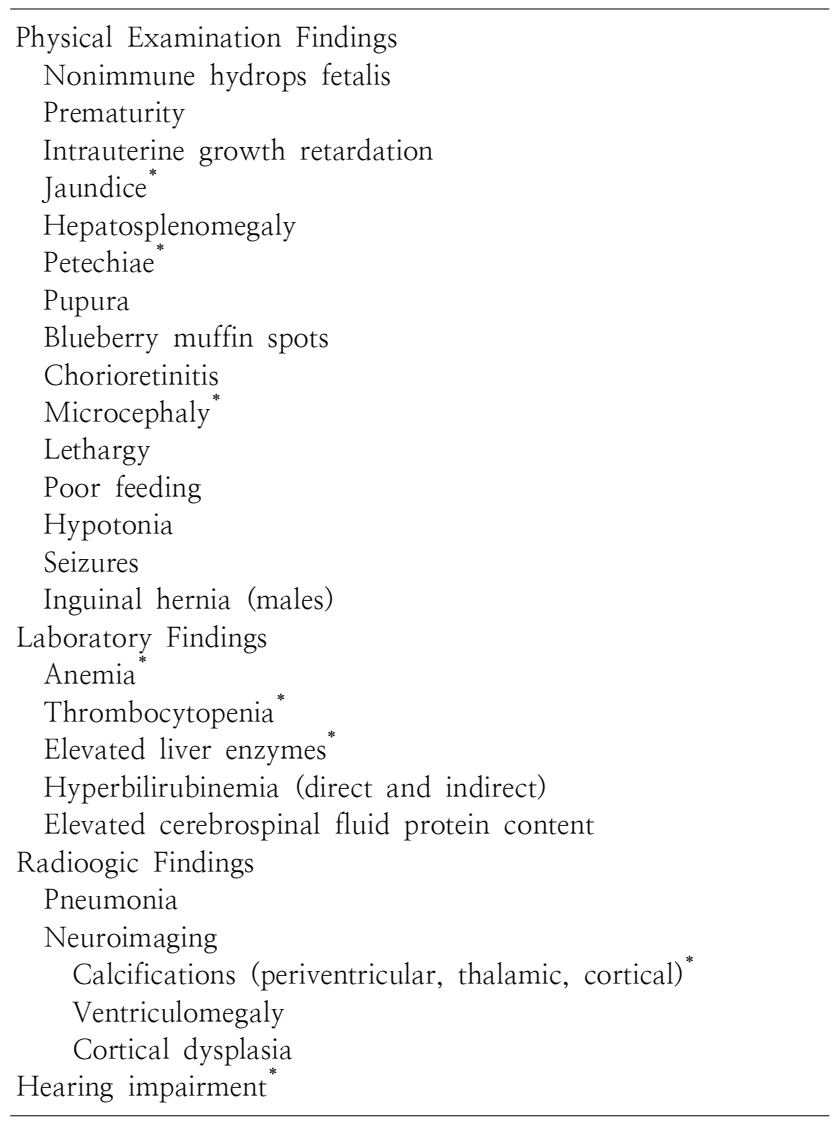

"Prominent features

Data from Stehel EK, et al. ${ }^{15)}$ may develop as a late findings of congenital CMV infection, usually occurring at $1-4$ months of age ${ }^{1,15)}$. CMV pneumonia in preterm infants has been associated with development or exacerbation of bronchopulmonary dyslasia (BPD) ${ }^{23)}$. And also postnatal administration of steroid for BPD in CMV-infected perterm infants has been associated with progression of CMV disease ${ }^{15)}$.

A major important issue in congenital CMV infection is cental nervous system (CNS) involvement including meningoencephalitis, calcification, microcephaly, disturbance of neuronal migration, germinal matrix cysts, ventriculomegaly and cerebellar hypoplasia ${ }^{6}$. CNS disease usually results in following symptoms and signs; lethargy, hypotonia, seizure, hearing deficit, or chorioretinitis. Some examples of abnormal magnetic resonance imaging (MRI) findings in infants with congenital CMV infection are suggested (Fig. 2).

Sensorineural hearing deficit (SNHD) may present at birth, either unilateral or bilateral, or can become later in childhood. Some patients have normal hearing for the first 6 years of life, but they can subsequently develop sudden or fluctuating hearing loss. Among children with hearing deficit, further deterioration of hearing occurs in 50\%, with the median age of first progression at 18 months of age (range, 2 to 70 months of age $)^{8,24,25)}$. Hearing loss apparently result from viral replication in the inner $e^{2 r^{26}}$.

Infants with symptomatic congenital CMV infection have a mortality rate of $20-30 \%{ }^{4,9)}$. Death are usually due to hepatic dysfunction, bleeding, disseminated intravascular coagulopathy or secondary bacterial infection ${ }^{4)}$.

\section{Perinatal infection}

The incubation period of perinatal CMV infection ranges between 4 and 12 weeks (mean, 8 weeks) ${ }^{1,15}$. The quantity of virus excreted by infants with perinatal infection is less than that developed in congenital infection, but this infection is also chronic, with viral excretion persisting for years ${ }^{1)}$.

Most term infants with perinatal CMV infection are asymptomatic, because the babies have maternal-transmitted CMV IgG antibody. In contrast, 15-25\% of infected preterm infants may develop clinical illnesses such as pneumonia, hepatitis or sepsis-like illness that present with apnea, bradycardia, hepatosplenomegaly, distended bowel, anemia, thrombocytopenia and abnormal hepatic function ${ }^{12,15)}$. Transfusion-acquired CMV infection in preterm babies with very low birth weight may develop severe symptoms 

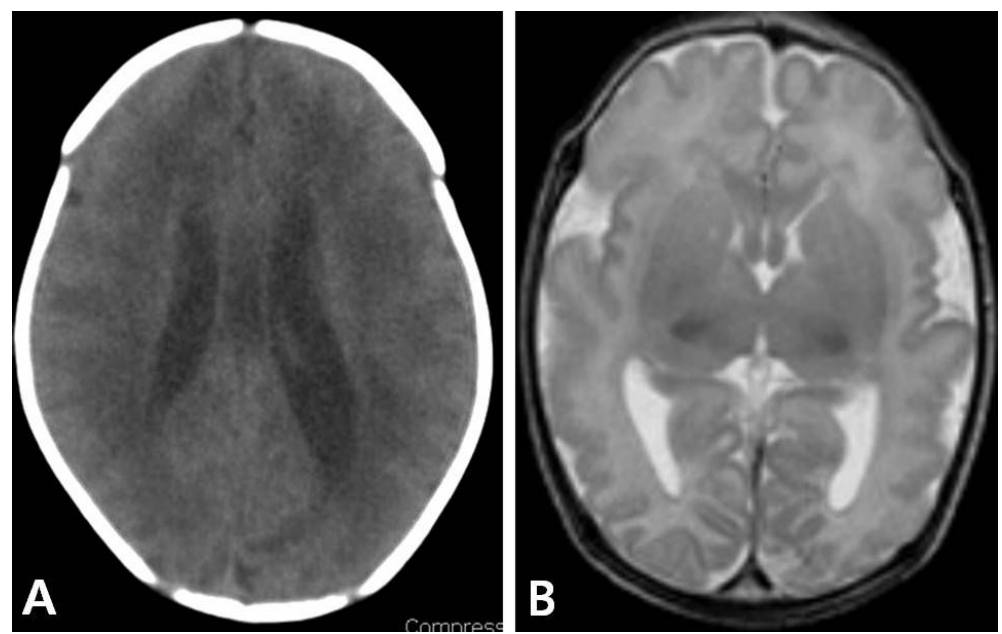

Fig. 2. Some examples of magnetic resonance imaging findings in infants with congenital cytomegalovirus infection. (A) Periventricular calcification and mild ventriculomegaly. (B) Diffuse polymicrogyria of cerebral hemispheres.

that resembled $\mathrm{CID}^{1)}$.

\section{Diagnosis}

Congenital CMV infection is diagnosed by isolation of virus from infants within the first 3 weeks of life ${ }^{3,13,15)}$. So it is difficult to differentiate whether CMV infection was acquired congenitally or perinatally in infants more than 3 weeks of age, unless clinical features of the former such as chorioretinitis, intracranial calcification, microcephaly and hearing loss, are present ${ }^{13,15)}$.

$\mathrm{CMV}$ is usually isolated from urine and saliva but may be isolated other body fluids including breast milk, cervicovaginal secretions, amniotic fluid, white blood cell, cerebrospinal fluid, stool and biopsy specimens. The best test for diagnosis of congenital or perinatal CMV infection is virus isolation or demonstration of CMV genetic material by polymerase chain reaction (PCR) from urine or saliva of newborn infants ${ }^{1,15)}$. The sensitivity of PCR with urine specimens is $89 \%$, and the specificity is $96 \%^{1,27)}$. Urine specimens should be refrigerated $\left(4^{\circ} \mathrm{C}\right)$ but never frozen or stored at room temperature. The recovery rate of viruses remains at $93 \%$ in urine after 7 days of refrigeration, decreasing to $50 \%$ after 1 month $^{5)}$. Although a fourfold rise in IgG titer in paired sera or a strong positive IgM antiCMV may be a useful finding suggesting infection, serologic assays are not recommended for diagnosis of CMV infection in neonates. Because IgG anti-CMV detected in newborn infants reflects transplacentally acquired maternal antibody and that can persist for up to 18 months of age ${ }^{15)}$. And also IgM assay has both false positive and false negative ${ }^{28,29)}$. Computed tomography (CT) is most sensitive to detect intracranial calcification. And MRI is particularly valuable for detection of the disorders of neuronal migration and other cerebral parenchymal lesions complicated with congenital CMV infection ${ }^{6}$.

Amniocentesis may be the most valuable single antenatal diagnostic test, and viral culture or PCR test of amniotic fluid are equally specific and sensitive ${ }^{2,5)}$. Quantitative PCR demonstrating $10^{5}$ genome equivalent per $\mathrm{mL}$ of amniotic fluid may be a predictor of symptomatic congenital infection $^{2)}$. Ultrasonographic fetal abnormalities in pregnant women with primary or recurrent CMV infection generally indicate symptomatic fetal infection. Reported sonographic abnormalities of the fetus include oligohydroamnios, IUGR, microcephaly, ventriculomegaly, intracranial calcification, hypoplastic corpus callosum, ascites, hepatosplenomegaly, hypoechogenic bowel, pleural and pericardial effusion, and hydrops ${ }^{16)}$.

\section{Treatment}

There are now two drugs for systemic treatment of congenital and perinatal CMV infection: ganciclovir and valganciclovir (oral prodrug of ganciclovir).

In a randomized controlled, multicenter, phase III study with ganciclovir $(6 \mathrm{mg} / \mathrm{kg} /$ dose intravenously every $12 \mathrm{hr}$ for a 6 week course) ${ }^{30)}$, it was carried out to treat newborn 
infants who have congenital CMV infection involving the $\mathrm{CNS}$, as defined by microcephaly, intracranial calcification, abnormal findings of cerebrospinal fluid, chorioretinitis and/ or hearing deficit. When tested at 6 months, $84 \%$ of treated infants maintained normal hearing or improved their hearing, in contrast to $59 \%$ of control infants. At 6 months followup, none of the treated infants had hearing deterioration, while $41 \%$ of control patients did. When tested 1 year of age or beyond $21 \%$ of treated and $68 \%$ of control infants had hearing deterioration. Primary ganciclovir-related toxicity was neutropenia. 63\% of treated infants developed neutropenia, compared with $21 \%$ of control infants.

In a pharmacokinetic and pharmacodynamic study of oral valgancyclovir in treatment of infants with congenital CMV infection $^{31)}$, it showed that a $6 \mathrm{mg} / \mathrm{kg}$ intravenous ganciclovir dose and $16 \mathrm{mg} / \mathrm{kg}$ oral valganciclovir provides similar systemic exposure to ganciclovir. In addition, treated patients with a 6 week course decreased in viral load of 0.7 log viral DNA copies/mL in urine. Toxicity of valganciclovir is similar to that of ganciclovir with $38 \%$ of subjects developing neutropenia.

Treatment with ganciclovir of a 6 week course can be considered for symptomatic infants with congenital CMV infection involving the CNS, but can not be routinely recommended ${ }^{15)}$. A 2 week course of ganciclovir may be beneficial in critically ill infants with symptomatic perinatal CMV infection. And additional 1-2 weeks of ganciclovir can be considered if symptoms and signs have not been $\mathrm{re}^{-}$ solved $^{12)}$

\section{Prognosis}

Infection during early pregnancy more often result in more severe sequelae than infection later in pregnancy. Approximately $50-90 \%$ of symptomatic survivors have long-term sequelae such as microcephaly, hearing loss, motor deficit (paresis/paralysis), cerebral palsy, mental retardation, seizure, ocular abnormalities (chorioretinitis, optic atrophy), autism and learning disabilities ${ }^{32)}$ (Table 2). In contrast, $10-15 \%$ of infant with congenital CMV infection who are asymptomatic at birth have long-term neurodevelopmental injury.

Factors associated with poor cognitive prognosis are microcephaly and abnormalities detected on brain $\mathrm{CT}^{4,6)}$. In contrast, children with normal findings on brain $\mathrm{CT}$ and normal head circumference have been revealed to have a good cognitive outcome ${ }^{33)}$. So radiologic findings of brain with MRI and CT may be the most specific and sensitive predictors of neurodevelopmental outcomes ${ }^{6)}$. Microcephaly dose not always persist, and dose not always result in later handicap. Infants who have microcephaly alone without other neurologic findings have relatively a good prognosis in early childhood ${ }^{34)}$. Chorioretinitis is nearly always indicative significant mental retardation and often lead to optic atrophy. It can also develop on several weeks after birth ${ }^{8)}$. SNHD, the most common sequelae of congenital CMV infection may occur in both symptomatic and asymptomatic infected infants. Although about $60 \%$ of infants with hearing loss is developed at birth or in neonatal period, at least 40 $\%$ may have delayed-onset loss ${ }^{6}$. Additionally progression of hearing loss in patients who had already SNHD has also been observed in about $60 \%$ of infants with through childhood and into adolescence ${ }^{15,25,35)}$. So all babies with congenital CMV infection should be followed at least school entry, and hearing test regularly performed to detect late deficit ${ }^{6,8)}$. Patient with disseminated symptomatic infection including petechiae or IUGR at birth and those with higher viral load at birth appear to have an increased risk of hearing loss ${ }^{1,35)}$.

Premature and ill full-term infants with serious perinatal CMV infection may be an increased risk of neurologic sequlae and psychomotor retardation, even though there dose not appear to be a higher rate of SNHD, microcephaly and chorioretinitis ${ }^{1,2)}$.

Table 2. Long-term Sequelae of Congenital Cytomegalovirus Infection in Children

\begin{tabular}{lcc}
\hline \multirow{2}{*}{ Sequelae } & \multicolumn{2}{c}{ Affected children, \% } \\
\cline { 2 - 3 } & Symptomatic & Asymptomatic \\
\hline Overall incidence & $50-90$ & $10-15$ \\
Hearing loss & $50-60$ & $7-15$ \\
Cognitive deficit & $50-70$ & -4 \\
Microcephaly & $35-40$ & -2 \\
Ocular abnormalities & $25-50$ & -3 \\
Seizures & $15-20$ & -1 \\
Motor deficit & $25-30$ & $<1$ \\
$\quad$ (mild to moderate) & & $<1$ \\
Motor deficit (severe) & $15-25$ & \\
\hline
\end{tabular}

${ }^{*}$ Rates reflect a range of incidence data reported in the pediatric literature.

Data from Schleiss $\mathrm{MR}^{32}$ 


\section{Prevention}

CMV is usually not very contagious, and its horizontal transmission requires direct contact with infected materials, such as different secretions that contain the virus, and less likely, formites. So adherence to standard precautions with good hand hygiene is effective to prevent CMV infection ${ }^{1,13)}$.

Preexisting maternal immunity to CMV affords significant protection to the fetus. In contrast, with maternal primary infection, the overall risk for delivering a symptomatic neonate is about $5 \%^{3,4,9)}$. So women of childbearing age should have CMV serologic tests, especially if they provide care for young children who are potential CMV excreters ${ }^{1}$, 2,36). And pregnant women who are CMV seronegative should be provided with information on prevention measures and reassured that common sense steps such as hand washing and avoiding contact with secretions should prevent this infection ${ }^{1,37)}$. Although newborn hearing screening programs may miss the late-onset hearing loss complicated in congenital CMV infection, routine screening of all newborns for CMV is not yet recommended ${ }^{38,39)}$.

Pasteurization $\left(72^{\circ} \mathrm{C}\right.$ for 5 seconds $)$ of breast milk can inactivate CMV completely without affecting nutritional and immunologic properties of milk, although freezing $\left(-20^{\circ} \mathrm{C}\right.$ for 3-7 days) will significantly decrease viral titers ${ }^{12,40}$, 41). Transfusion-acquired CMV infection is eliminated by administration of CMV antibody-negative blood products and filtration of blood to remove white blood cells ${ }^{12)}$.

CMV vaccine ultimately may be an important preventive measure, but are not yet successful.

\section{References}

1) Stagno $S$, Britt W. Cytomegalovirus infections. In : Remington JS, Klein JO, Wilson CB, Baker CJ, editors. Infectious diseases of the fetus and newborn infant. 6th ed. Philadelphia : Saunders, 2006:739-81.

2) Stagno S. Cytomegalovirus. In : Kliegman RM, Behrman RE, Jenson HB, Stanton BF, editors. Nelson textbook of pediatrics. 18th ed. Philadelphia : Saunders, 2007:1377-9.

3) Trincado DE, Rawlinson WD. Congenital and perinatal infections with cytomegalovirus. J Paediatr Child Health 2001;37: 187-92.

4) Malm G, Engman ML. Congenital cytomegalovirus infections. Semin Fetal Neonatal Med 2007;12:154-9.

5) Undin $\mathrm{MH}$, Gonik B. Perinatal infections. In : Martin RJ, Fanaroff AA, Walsh MC, editors. Neonatal-perinatal medicine. 8th ed. St Louis : Mosby, 2006:840-82.

6) Volpe JJ. Neurology of the newborn. 5th ed. Philadelphia : Saunders, 2008:851-915.

7) Nassetta L, Kimberlin D, Whitley R. Treatment of congenital cytomegalovirus infection: implications for future therapeutic strategies. J Antimicrob Chemother 2009;63:862-7.

8) Isaacs D, Moxon ER. Hand book of Neonatal infection: A practical guide. 1st ed. London : WB Saunders Co, 2000; 378-88.

9) Baley JE, Toltzis P. Perinatal viral infections. In : Martin RJ, Fanaroff AA, Walsh MC, editors. Neonatal-perinatal medicine. 8th ed. St Louis : Mosby, 2006:429-53.

10) Pass RF, Fowler KB, Boppana SB, Britt WJ, Stagno S. Congenital cytomegalovirus infection following first trimester maternal infection: symptoms at birth and outcome. J Clin Virol 2006;35:216-20.

11) Fowler KB, Stagno S, Pass RF, Britt WJ, Boll TJ, Alford CA. The outcome of congenital cytomegalovirus infection in relation to maternal antibody status. N Engl J Med 1992;326: 663-7.

12) AAP committee on infectious diseases. cytomegalovirus infection. In: Pickering LK, Baker CJ, Kimberlin DW, Long SS, editors. Red book. 28th ed. IL:American academy of pediatrics, 2009:275-80.

13) Demmler-Harrison GJ. Cytomegalovirus. In : Feigin RD, Cherry JD, Demmler-Harrison GJ, Kaplan SL, editors. Textbook of pediatric infectious diseases. 6th ed. Philadelphia : Saunders, 2009:2022-43.

14) Kim JH, Chung EJ, Park HK, Moon SJ, Choi SM, Oh SH. Postnatal cytomegalovirus infection in an extremely premature infant transmitted via breast milk: A case report. Korean J Pediatr 2009;52:1053-8.

15) Stehel EK, Sánchez PJ. Cytomegalovirus Infection in the Fetus and Neonate. NeoReviews 2005;6:e38-e45.

16) Revello MG, Gerna G. Pathogenesis and prenatal diagnosis of human cytomegalovirus infection. J Clin Virol 2004;29:71-83.

17) Kumar ML, Nankervis GA, Cooper AR, Gold E. Postnatally acquired cytomegalovirus infections in infants of CMV-excreting mothers. J Pediatr 1984;104:669-73.

18) Hamprecht K, Maschmann J, Vochem M, Dietz K, Speer CP, Jahn G. Epidemiology of transmission of cytomegalovirus from mother to preterm infant by breastfeeding. Lancet 2001:357: $513-8$.

19) Boppana SB, Fowler KB, Britt WJ, Stagno S, Pass RF. Symptomatic congenital cytomegalovirus infection in infants born to mothers with preexisting immunity to cytomegalovirus. Pediatrics 1999;104:55-60.

20) Boppana SB, Rivera LB, Fowler KB, Mach M, Britt WJ. Intrauterine transmission of cytomegalovirus to infants of women with preconceptional immunity. N Engl J Med 2001;344: 1366-71.

21) Hamprecht K, Maschmann J, Jahn G, Poets CF, Goelz R. Cytomegalovirus transmission to preterm infants during lactation. J Clin Virol 2008;41:198-205.

22) Yeager AS, Grumet FC, Hafleigh EB, Arvin AM, Bradley JS, Prober CG. Prevention of transfusion-acquired cytomegalovirus infections in newborn infants. J Pediatr 1981;98:281-7.

23) Sawyer MH, Edwards DK, Spector SA. Cytomegalovirus infec- 
tion and bronchopulmonary dysplasia in premature infants. Am J Dis Child 1987;141:303-5.

24) Fowler KB, Boppana SB. Congenital cytomegalovirus (CMV) infection and hearing deficit. J Clin Virol 2006;35:226-31.

25) Fowler KB, McCollister FP, Dahle AJ, Boppana S, Britt WJ, Pass RF. Progressive and fluctuating sensorineural hearing loss in children with asymptomatic congenital cytomegalovirus infection. J Pediatr 1997;130:624-30.

26) Cheeran MC, Lokensgard JR, Schleiss MR. Neuropathogenesis of congenital cytomegalovirus infection: disease mechanisms and prospects for intervention. Clin Microbiol Rev 2009;22: 99-126.

27) Demmler GJ, Buffone GJ, Schimbor CM, May RA. Detection of cytomegalovirus in urine from newborns by using polymerase chain reaction DNA amplification. J Infect Dis 1988; 158:1177-84.

28) Kim DW, Kwack H, Jang SH, Kang IS, Lee HJ, Choi JW, et al. Cytomegalovirus infection in children: The significance of CMV specific IgM antibody test and virus isolation in the urine. J Korean Pediatr Soc 1992;35:890-901.

29) Revello MG, Zavattoni M, Baldanti F, Sarasini A, Paolucci S, Gerna G. Diagnostic and prognostic value of human cytomegalovirus load and IgM antibody in blood of congenitally infected newborns. J Clin Virol 1999;14:57-66.

30) Kimberlin DW, Lin CY, Sánchez PJ, Demmler GJ, Dankner W, Shelton M, et al. Effect of ganciclovir therapy on hearing in symptomatic congenital cytomegalovirus disease involving the central nervous system: a randomized, controlled trial. J Pediatr 2003;143:16-25.

31) Kimberlin DW, Acosta EP, Sánchez PJ, Sood S, Agrawal V, Homans J, et al. Pharmacokinetic and pharmacodynamic assessment of oral valganciclovir in the treatment of symptomatic congenital cytomegalovirus disease. J Infect Dis 2008;197:
836-45.

32) Schleiss MR. Congenital Cytomegalovirus Infection: Update on Management Strategies. Curr Treat Options Neurol 2008; 10:186-192.

33) Noyola DE, Demmler GJ, Nelson CT, Griesser C, Williamson WD, Atkins JT, et al. Early predictors of neurodevelopmental outcome in symptomatic congenital cytomegalovirus infection. J Pediatr 2001;138:325-31.

34) Ramsay ME, Miller E, Peckham CS. Outcome of confirmed symptomatic congenital cytomegalovirus infection. Arch Dis Child 1991;66:1068-9.

35) Rivera LB, Boppana SB, Fowler KB, Britt WJ, Stagno S, Pass RF. Predictors of hearing loss in children with symptomatic congenital cytomegalovirus infection. Pediatrics 2002;110: 762-7.

36) Lee KY. Seroepidemiology of cytomegalovirus in Taejon, Korea. J Korean Pediatr Soc 1998;41:754-9.

37) Adler SP, Finney JW, Manganello AM, Best AM. Prevention of child-to-mother transmission of cytomegalovirus among pregnant women. J Pediatr 2004;145:485-91.

38) Fowler KB, Dahle AJ, Boppana SB, Pass RF. Newborn hearing screening: will children with hearing loss caused by congenital cytomegalovirus infection be missed? J Pediatr 1999;135:60-4.

39) Demmler GJ. Screening for congenital cytomegalovirus infection: a tapestry of controversies. J Pediatr 2005;146:162-4.

40) Yasuda A, Kimura H, Hayakawa M, Ohshiro M, Kato $Y$, Matsuura $\mathrm{O}$, et al. Evaluation of cytomegalovirus infections transmitted via breast milk in preterm infants with a real-time polymerase chain reaction assay. Pediatrics 2003;111:1333-6.

41) Jim WT, Shu CH, Chiu NC, Kao HA, Hung HY, Chang JH, et al. Transmission of cytomegalovirus from mothers to preterm infants by breast milk. Pediatr Infect Dis J 2004;23: $848-51$ 